\title{
Implications of sperm banking for health-related quality of life up to 1 year after cancer diagnosis
}

\author{
A Pacey ${ }^{*}{ }^{1}, \mathrm{H} \mathrm{Merrick}^{2}$, E Arden-Close ${ }^{2}, \mathrm{~K} \mathrm{Morris}^{1}, \mathrm{R} \mathrm{Rowe}^{2}$, D Stark ${ }^{3}$ and C Eiser ${ }^{2}$ \\ ${ }^{1}$ Academic Unit of Reproductive and Developmental Medicine, Department of Human Metabolism, University of Sheffield, \\ Level 4, The Jessop Wing, Tree Root Walk, Sheffield S10 2SF, UK; ${ }^{2}$ Department of Psychology, University of Sheffield, Sheffield \\ S10 2TP, UK and ${ }^{3}$ Leeds Institute of Molecular Medicine, Leeds Institute of Oncology and St James's University Hospital Leeds, \\ and Level 4, St James's Institute of Oncology, Bexley Wing, St James's University Hospital, Beckett Street, Leeds LS9 7TF, UK
}

Background: Sperm banking is recommended for all men diagnosed with cancer where treatment is associated with risk of longterm gonadatoxicity, to offer the opportunity of fatherhood and improved quality of life. However, uptake of sperm banking is lower than expected and little is known about why men refuse. Our aims were to determine: (i) demographic and medical variables associated with decisions about banking and (ii) differences in quality of life between bankers and non-bankers at diagnosis (Time 1 (T1)) and 1 year later (Time 2 (T2)).

Methods: Questionnaires were completed by 91 men (response rate $=86.67 \%)$ at T1 and $78(85.71 \%$ response rate) at T2.

Results: In all, 44 (56.41\%) banked sperm. They were younger and less likely to have children than non-bankers. In a subset of men who were not sure if they wanted children in the future $(n=36), 24$ banked sperm. Among this group, those who banked were younger, more satisfied with clinic appointments and less worried about the health of future children. At T2, there were no differences in quality of life between bankers and non-bankers.

Conclusion: For those who are uncertain about future reproductive plans, decisions depend on their health on diagnosis and satisfaction with clinic care. We conclude that extra care should be taken in counselling younger men who may have given little consideration to future parenting. Results support previous findings that the role of the doctor is vital in facilitating decisions, especially for those who are undecided about whether they wanted children in the future or not.

Survival rates for most cancers continue to improve, but physical and psychological late effects are increasingly recognised (Ganz, 2010), including risks of infertility (Wallace and Thomson, 2003; Pacey, 2007). As infertility cannot always be predicted, it is recommended that sperm banking is offered to all postpubertal male subjects where there is a risk of long-term gonadal damage (National Collaborating Centre for Women's and Children's Health, 2004; ESHRE, 2004; Lee et al, 2006; Royal College of Physicians, 2007). In this way, men who survive cancer have the opportunity to father a child after treatment with positive implications for their health-related quality of life (HRQoL).

Although young men diagnosed with cancer are concerned about the risk of infertility (Schover et al, 1999; Tschudin and
Bitzer, 2009), data indicate that sperm banking services are underutilised (Pacey and Eiser, 2011). Previous work (Magelssen et al, 2005; Girasole et al, 2007; Klosky et al, 2009) suggests only $24-31 \%$ of men accept the opportunity to bank sperm at diagnosis. The most common reasons to decline the offer of banking sperm are not wanting children in the future, and prior sterilisation of them (vasectomy) or their partner (tubal ligation). Those who are single at the time of diagnosis feel too old to have children or are advised that sperm banking is not necessary are also less likely to bank (Gilbert et al, 2011; Quinn et al, 2011). Concern about treatment delays (Schover et al, 1999) and pressures to begin cancer treatment quickly may cause decisions about sperm banking to be hurried or poorly considered (Zapzalka et al, 1999;

*Correspondence: Dr A Pacey; E-mail: a.pacey@Sheffield.ac.uk

Received 19 September 2012; revised 12 January 2013; accepted 19 January 2013; published online 7 March 2013

(C) 2013 Cancer Research UK. All rights reserved 0007 - 0920/13 
Schover et al, 2002). Some men are concerned about abnormalities and teratogenic risk for children born from frozen sperm (Lass et al, 2001), and this may influence their decision to accept the offer.

Conversely, those who do decide to bank sperm are typically of higher socioeconomic status (Klosky et al, 2009), younger, less likely to have children before diagnosis (Schover et al, 2002) and more optimistic about survival (Achille et al, 2006). Yee et al (2011) found a major factor in men's decision to bank was future family planning and others commented on the psychological benefits of banking (Saito et al, 2005) and how it gave them a 'sense of hope' and 'peace of mind' before starting treatment (Pacey, 2003; Eiser et al, 2011).

Oncologists also have a key role in men's decisions (Schover et al, 2002; Saito et al, 2005). Both Eiser et al (2011) and Yee et al (2011) found many men banked sperm simply because it was what their doctor/oncologist advised: they attended appointments at the sperm bank in much the same way as they attended for blood tests and scans. The decision to bank sperm necessitates more hospital appointments and increased contact with clinic staff, so that those who are more satisfied with their initial care may be more likely to accept the doctor's recommendations (Loblaw et al, 1999). Conversely, barriers to effective communication between doctor and patient, or the lack of relevant or easily accessible information about sperm banking, may hamper decision-making (Achille et al, 2006; Gilbert et al, 2011; Quinn et al, 2011).

The wish to have children after treatment is consistently given as the reason why men bank sperm, but this raises the question about what motivates men to bank when they are unsure about whether or not they want children in the future. Given the relatively young age on diagnosis of some cancers, (Office for National Statistics, 2012), it is likely that many men diagnosed with testicular cancer may not have given much thought to starting a family. Previous research offers only limited perspectives about these young men and failure to recognise this may partly explain why statistics suggest that men are reluctant to take up banking services: they are undecided about how much they want children in the future (whether or not they already have children) and therefore decline the offer without much thought.

With few exceptions, past work has focused on the variables associated with the decision to bank but has not considered the longer-term consequences for HRQoL. Most work suggests that long-term HRQoL among men following testicular cancer is as good as the general population (Rossen et al, 2009), although there may be some compromise in physical HRQoL and among those with more side effects (Mykletun et al, 2005). Cancer survivors who chose not to bank and subsequently became infertile after treatment reported substantial psychosocial distress (Green et al, 2003; Neal et al, 2007). In that sperm banking has been construed as a means to enhance long-term HRQoL, we specifically evaluated any differences between bankers and non-bankers over the first year following diagnosis, with the expectation that bankers might report higher HRQoL.

Our aims were therefore first to identify medical, demographic and psychological variables on diagnosis (T1) and 1 year later (T2), which differentiate between bankers and non-bankers, and second to determine HRQoL among a sample of young men where treatment poses a risk to their fertility. We conducted separate analyses including the subset of men who were unsure at T1 about their desire for fatherhood in the future.

\section{MATERIALS AND METHODS}

Procedure. Between July 2008 and August 2010, a sequential cohort of men diagnosed with either testicular cancer or a haematological disorder in two teaching hospitals in the north of
England (Sheffield and Leeds) were approached to take part in the study. These groups were selected because they represent the most common diagnoses in men of reproductive age and the most frequently referred reasons for sperm banking (Pacey and Eiser, 2011). Eligibility criteria included male subjects aged 18-45 years, diagnoses of testicular or haematological cancer with good prognoses and undergoing treatment with curative intent, no known mental health problems and sufficient English language ability to provide written informed consent and complete questionnaires. A research nurse approached eligible patients at the clinic appointment when sperm banking was discussed and men were invited to participate regardless of their decision to bank sperm. Meetings were held between the two medical teams throughout the study to ensure standard procedures. Men who agreed to participate were asked to complete questionnaires as soon as possible (T1) and again 1 year later at a routine follow-up visit (T2). Extra time was given at each appointment for men to complete their questionnaires. All recruitment procedures were approved by the Trent Research Ethics Committee (Ref: 07/H0405/61).

Measures. Background information was collected about age (years), partner status (single, partner but not living together, married/living with partner, divorced/separated or widowed), age left full-time education (16 or under, 17-18, 19-21 or 21+), employment (work full-time, work part-time, on sick leave, student, homemaker, retired, unemployed, other), ethnicity (white, mixed, Asian or Asian British, Black or Black British, Chinese or Chinese British, other), living status (alone, with friends, with a partner, with parents, other) and number of children (biological, adopted, born using sperm from a donor and step-children).

T1 self-report measures. Health-related quality of life (QLQ-C30) is a 30 -item measure, which is typically scored to yield a global health status scale, five functional scales and nine symptom scales/ items (Aaronson et al, 1993). The five functional scales include physical function (five items), role function (two items), emotional function (four items), social function (two items) and cognitive function (two items). The nine symptom scales include fatigue (three items), nausea and vomiting (two items), and pain (two items), and single items to assess dyspnoea, insomnia, appetite loss, constipation, diarrhoea and financial impact. Higher scores on functional scales and global health status indicate good HRQoL, whereas higher scores on symptom items and scales represent poor HRQoL. The measure has been found to yield high test-retest reliability in patients with various cancer diagnoses (Hjermstad et al, 2005). We followed a recent approach to analyses described by Hinz et al (2012), which results in the calculation of three scores: function, symptoms and a total score.

Views of clinic appointments were assessed using the Princess Margaret Hospital Patient Satisfaction With Doctor Questionnaire (PMH/PSQ-MD). This scale was developed to assess satisfaction among cancer patients and includes 29 items grouped into four subscales (information exchange, interpersonal skills, empathy and quality of time; Loblaw et al, 1999). Excellent reliability $(\alpha=0.97)$ and validity have been demonstrated. We calculated a total satisfaction score based on two subscales measuring 'Information exchange' (nine items) and 'Quality of time' (five items). Responses were made on five-point Likert scales from 'strongly agree' to 'strongly disagree', with higher scores representing greater satisfaction.

Illness perceptions (Brief Illness Perception QuestionnaireRevised: BIPQR; Broadbent et al, 2006): The BIPQR includes eight items, of which five assess cognitive illness representations (consequences, timeline, personal control, treatment control and identity), two assess emotional representations (concern and emotions) and one assesses illness comprehensibility. An additional item, 'How much do you think your illness has affected your 
fertility (ability to have children)' was added (but was scored separately). All items were rated on a 0 to 10 response scale, with higher scores reflecting a more threatening view of the illness. A mean score based on all the items, as well as the individual items, were used in the analysis.

Views about sperm banking: Based on our literature review and clinical experience, we constructed a 15-item measure of men's views about sperm banking (e.g. I don't think my fertility is good enough to make banking worthwhile; I understand the benefits of banking before cancer treatment). Responses were made on fourpoint Likert scales from 'strongly agree' to 'strongly disagree'.

Views about parenting: We used five questions originally described by Schover et al $(1999,2002)$ to assess men's attitudes to having children in the future, 'How much has your experience of cancer affected your wish to have children in future?' 'How much do you want to have a child in future?', 'I worry that children born from banked sperm will have health problems', 'I worry that my cancer treatment could cause health problems for any child born afterwards' and 'Before your cancer diagnosis, were you ever worried that you had fertility problems?' Responses were made on five-point scales with appropriate end points (e.g. 'strongly agree' to 'strongly disagree'). The five items were analysed individually.

Information about fertility: A series of multiple-choice questions was used to determine the sources of information about possible infertility after cancer treatment and the availability of banking sperm (referral doctor, general practitioner nurse, social worker, oncologist, other health professional, family/friend or none of the above). Men were also asked to indicate if they accessed any written information (booklet, websites or other). One or more options could be ticked for each question.

T2 self-report measures. In addition to the above, at T2 four questions were asked about how many samples the men banked $(0,1,2-3,4-5$, can't remember), the quality of their banked samples ('I did not have any sperm to bank', 'good enough for fertility treatment' or 'don't know'), how confident they were that they made the right decision about banking and how important it is to know about changes in their fertility (rated on five-point Likert scales 'not at all' to 'very'). Each of these items was analysed individually.

Views about fertility included six questions about men's understanding about changes in their fertility after cancer treatment (Pacey et al, 2012). Responses were made on five-point Likert scales from 'strongly agree' to 'strongly disagree'. Two items measured men's confidence in fertility recovery: 'I am certain my fertility has already or will recover' and 'I am confident my fertility is normal/as good as any other man of my age'. Higher scores represented higher confidence in fertility recovery. Four items measured Importance of fertility monitoring: 'I don't want to know if my fertility has recovered or not', 'Information about my fertility will make no difference to my behaviour', 'There are worse things to worry about than being infertile' and 'I like to know as much as possible about the effects of treatment on my fertility'. Higher scores represent greater importance placed on monitoring fertility.

Medical and sperm banking information. Information on diagnosis, treatment and oncology follow-ups was obtained from medical records and information about the banked sperm was collected for those who decided to bank sperm. This included information on the prefreeze sample quality and also the consent given with regard to the use of banked sperm.

Analysis. All data were entered independently by two authors and checked for accuracy using SPSS version 16. Continuous variables were standardised before analysis. Independent samples $t$-tests and $\chi^{2}$ analyses were used to check for differences between study sites. For our sample, we examined the association between banking decision at T1 and demographic, medical and psychological variables using univariate logistic regression analyses. The extent to which these simple relationships were independent of each other was determined by multivariable hierarchical logistic regression analysis. Following Hosmer and Lemeshow (2000), we tested for significant non-linearity in the relationship of continuous predictors with the logit of the dependent variable. In multiple predictor models, we inspected for evidence of multicollinearity. Differences between bankers and non-bankers in HRQoL at T1 and $\mathrm{T} 2$ were explored using repeated measures ANOVA with one between-participants factor (Bank: bankers vs non-bankers) and one within-participants factor (Time: T1 vs T2). Independent samples $t$-tests were used to compare bankers and non-bankers on items asked at $\mathrm{T} 2$ only.

We created a subset of men who were unsure on diagnosis about whether they wanted children in the future by excluding all men who responded 'definitely want a child in the future' or 'definitely do not want a child in the future' to the question 'How much do you want to have a child in the future'. We used univariate logistic regression analyses to identify predictors of banking in this subsample. We did not construct a multiple predictor model with these data owing to the small sample size.

Treatment of measured variables. To create meaningfully sized groups, background variables were dichotomised as follows: partner status (partner vs single/separated), age left full-time education (under 18 years $v s$ over 18 years), employment (working full/part-time $v s$ not working), ethnicity (white $v s$ other) and living status (partner $v s$ other).

Scores on the EORTC QLQ-C30 were calculated using the algorithms provided by the EORTC group, where scores are linearly transformed to give a range of 0-100 (Fayers et al, 1995). Following the method tested by Hinz et al (2012), we calculated three sum scores: function, symptoms and a total score. This method was chosen in preference to averaging across the 15 separate items, to prevent higher weight being given to scales with more than one response (e.g. physical function $=5$; symptoms $=$ three symptom scales: pain, fatigue and nausea//vomiting and six single items) than those with fewer items. A total score was calculated by reverse coding the symptom items and averaging all the function and symptom scales, along with the global health status scale. Higher scores on the function and total scores represent higher HRQoL, but higher scores on the symptoms score equal low HRQoL. As expected, the distribution of the HRQoL scores deviated substantially from normality, and scores were therefore dichotomised using median splits, as described by previous authors (Hayden et al, 2004; Snyder et al, 2009). Subsequent comparisons were made between the highest- and lowest-scoring halves.

Most scales were found to have good reliability $(\alpha \geqslant 0.70)$ : satisfaction with clinic appointments $(\alpha=0.87)$, information exchange (0.74) and quality of time (0.85), and illness perceptions (0.70). The three HRQoL scales all had good reliability: function (0.76), symptom (0.82) and total score (0.90). On views to fertility, the same factor solution reported by Pacey et al (2012) was present in this population. However, while confidence in fertility recovery had a high reliability (0.86), importance of fertility monitoring did not (0.51), and the items in this scale were analysed separately. For the 'views about sperm banking' items, a principal components analysis failed to show a simple multifactorial structure due to cross-loadings on several items. Therefore, all items were analysed separately.

\section{RESULTS}

There were no differences between the two hospitals on any measured demographic, medical or psychological variables, and 
therefore data were combined in subsequent analyses. Some men completed the T1 questionnaire before banking $(N=16,36.4 \%)$, whereas the remainder banked sperm between 2 and 4 weeks previously $(N=28,63.6 \%)$. Comparisons were made between men who completed questionnaires before banking and those who completed them immediately after banking, but there were no significant differences on any variables and therefore these groups were also combined in subsequent analyses.

Of the 105 men identified as eligible to take part in the study, 91 $($ Sheffield $=68 ; \quad$ Leeds $=23)$ returned questionnaires at T1 (response rate: $86.7 \%$ ) and 78 men (85.7\%: Sheffield $=58$; Leeds $=20$ ) returned questionnaires at 1 -year follow-up (T2). Of the 13 men who did not return questionnaires at T2, 7 were lost to follow-up or had relocated, 5 had died and 1 was in palliative care. All further analyses were conducted for the men who returned questionnaires at both time points $(N=78)$. Demographic characteristics for the whole sample and for those who chose to bank sperm $(N=44)$ and those who did not $(N=34)$ are shown in Table 1 and medical information in Table 2.

All men remembered being told about the risks of infertility from cancer treatment and that they could bank sperm before treatment. Many (65.4\%) reported receiving the information from more than one source. At both time points, most men ( $\mathrm{T} 1=71.8 \%$; $\mathrm{T} 2=69.2 \%$ ) reported being told about the infertility risk by their oncology consultant, and/or a nurse $(\mathrm{T} 1=55.1 \%$; $\mathrm{T} 2=48.7 \%)$, and/or by their General Practitioner (GP (T1 $=52.6 \%$; $\mathrm{T} 2=51.3 \%)$. The same three sources were also most likely to mention the possibility of sperm banking: oncology consultant $(\mathrm{T} 1=71.8 \% ; \mathrm{T} 2=66.2 \%)$ and $/$ or nurse $(\mathrm{T} 1=53.8 \%, \mathrm{~T} 2=50.6 \%)$ and/or their GP $(\mathrm{T} 1=50 \%$; $\mathrm{T} 2=42.9 \%)$. At $\mathrm{T} 1,57.7 \%$ of men reported they had seen written information about sperm banking, $5.1 \%$ from multiple sources. In all, 40 men (51.3\%) had seen a brochure/booklet about sperm banking, 8 (10.3\%) had checked websites for information.

Demographic, medical and psychological variables predicting the banking decision on diagnosis (T1). According to medical records, 44 men $(56.4 \%$ : Sheffield $=30$; Leeds $=14)$ chose to bank their sperm before commencing cancer treatment. In all, 16 (37.2\%) banked one sample, 21 (48.8\%) banked two and 7 (14\%) banked three samples. Younger men and those who did not already have children were more likely to bank sperm (Table 1) but there were no significant differences in terms of their relationship status, age when they left full-time education, employment status, living status or ethnicity. There were also no significant differences between bankers and non-bankers in terms of medical variables such as diagnosis (testicular vs other), treatment given, any additional medical conditions or the time (weeks) between referral to oncologist and beginning treatment (Table 2).

Variables that predicted the banking decision at T1 included a greater desire for children in the future $(\mathrm{OR}=8.19 ; 95 \% \mathrm{CI}=$ 3.53-19.01; $P<0.001$ ), reporting that the experience of cancer had increased the wish to have children $(\mathrm{OR}=2.64 ; 95 \% \mathrm{CI}=$ $1.15-6.09 ; P<0.001)$. They also were more likely to think they would have more regrets at a later date if they did not bank $(\mathrm{OR}=3.51 ; 95 \% \mathrm{CI}=1.93-6.39 ; P<0.001)$. The item 'knowing my sperm is/was banked makes me feel more of a complete man', did not meet the assumption of linearity of the logit and was dichotomised (agree/disagree) and entered as a categorical predictor. Men who agreed with this statement were significantly more likely to bank sperm $(\mathrm{OR}=3.40 ; 95 \% \quad \mathrm{CI}=1.09-0.59$; $P=0.035)$. At $\mathrm{T} 1$, those who banked sperm reported better function, lower symptom and better total HRQoL scores than those who did not bank sperm. Bankers were more likely to be among the highest scoring 50\% in total HRQoL (bankers $60.47 \%$; non-bankers $35.29 \%, P=0.028$ ); function (bankers $60.45 \%$; nonbankers $32.35 \% ; P=0.014$ ) and the lowest scoring $50 \%$ on symptom
Table 1. Background information for total sample and for bankers and non-bankers at Time 1

\begin{tabular}{|c|c|c|c|c|}
\hline & $\begin{array}{c}\text { Total } \\
(N=78)\end{array}$ & $\begin{array}{c}\text { Banker } \\
(N=44)\end{array}$ & $\begin{array}{c}\text { Non- } \\
\text { banker } \\
(N=34)\end{array}$ & $\begin{array}{c}\text { Odds ratio } \\
(95 \% \mathrm{Cl})\end{array}$ \\
\hline
\end{tabular}

Relationship status

\begin{tabular}{|l|l|l|l|l|}
\hline Partner & $53(67.9 \%)$ & $30(68.2 \%)$ & $23(67.6 \%)$ & $1.03(0.39-2.67)$ \\
Other & $25(32.1 \%)$ & $14(31.8 \%)$ & $11(32.4 \%)$ & \\
\hline
\end{tabular}

Age left full-time education

\begin{tabular}{|l|l|l|l|l|}
\hline $\begin{array}{l}\text { Under 18 } \\
\text { years } \\
\begin{array}{l}\text { Over 18 } \\
\text { years }\end{array}\end{array}$ & $48(61.5 \%)$ & $25(56.8 \%)$ & $23(67.6 \%)$ & $0.63(0.25-1.60)$ \\
\hline
\end{tabular}

Employment status

\begin{tabular}{|l|l|l|l|l|}
\hline Working & $49(62.8 \%)$ & $29(65.9 \%)$ & $20(58.8 \%)$ & $1.35(0.54-3.41)$ \\
Not working & $29(37.2 \%)$ & $15(34.1 \%)$ & $14(41.2 \%)$ & \\
\hline
\end{tabular}

Living status

\begin{tabular}{|l|l|l|l|l|}
\hline With partner & $50(64.1 \%)$ & $27(61.4 \%)$ & $23(67.6 \%)$ & $0.76(0.30-1.95)$ \\
Other & $28(35.9 \%)$ & $17(38.6 \%)$ & $11(32.4 \%)$ &
\end{tabular}

\section{Ethnic status}

\begin{tabular}{|l|c|c|c|c|}
\hline White & $68(87.2 \%)$ & $37(84.1 \%)$ & $31(91.2 \%)$ & $0.51(0.12-2.15)$ \\
Other & $10(12.8 \%)$ & $7(15.9 \%)$ & $3(8.8 \%)$ & \\
\hline
\end{tabular}

Have children already

\begin{tabular}{|l|l|l|l|l|}
\hline Yes & $36(46.2 \%)$ & $13(29.5 \%)$ & $23(67.6 \%)$ & $4.99(1.90-13.12)^{\star}$ \\
No & $42(53.8 \%)$ & $31(70.5 \%)$ & $11(32.4 \%)$ & \\
\hline
\end{tabular}

Age at questionnaire (years)

\begin{tabular}{l|c|c|c|c|}
\hline Mean (s.d.) & $\begin{array}{l}33.00 \\
(7.71)\end{array}$ & $\begin{array}{l}29.49 \\
(6.71)\end{array}$ & $\begin{array}{l}37.55 \\
(6.50)\end{array}$ & $0.26(0.14-0.50)^{*}$ \\
\hline $\begin{array}{l}\text { Abbreviations: } \mathrm{Cl}=\text { confidence interval; s.d. }=\text { standard deviation. *Significance level } \\
P<0.001 .\end{array}$ \\
\hline
\end{tabular}

scores (bankers 34.88\%; non-bankers 34.88\%; $P=004$ ). Illness perceptions, satisfaction with information exchange or quality of time were not associated with the decision to bank sperm.

Those variables above that significantly predicted banking in univariate models were entered into a hierarchical logistic regression model to identify those that uniquely contributed to the decision to bank (Table 3 ). In the first step, age and whether they already have children was entered, followed by total HRQoL and in the final step the views about sperm banking and desire for children items were entered. The full model was significant in distinguishing between bankers and non-bankers, $\chi^{2}(7)=52.25$, $P<0.001$, with 'desire for children in the future' being the only variable to distinguish between bankers and non-bankers.

Differences between bankers and non-bankers 1 year after diagnosis (T2). At T2, both bankers and non-bankers were confident that they had made the right decision about banking sperm $(4.59 \pm 0.69$ and $4.20 \pm 1.29$, respectively) and there was no significant difference in their level of confidence $(t(32.02)=-1.40 ; P=0.170)$. Bankers felt it was more important to know about changes in fertility $(4.39 \pm 0.92)$ compared with non-bankers $\quad(3.07 \pm 1.51) \quad(t(43.72)=-4.28, \quad P<0.001) \quad$ and reported significantly greater confidence in fertility recovery $(3.45 \pm 0.90$ vs $2.94+0.74, t(75)=-2.68 ; P=0.009)$. Men who banked sperm agreed to a significantly greater extent with the 
statement 'I like to know as much as possible about the effects of treatment on my fertility' $(3.86 \pm 1.05$ vs $3.06 \pm 1.17 ; t(75)=$ $-3.17 ; P=0.002)$ and disagreed with the statement 'I don't want to know if my fertility has recovered or not' $(4.30 \pm 1.05$ vs $2.97 \pm 1.21 ; t(75)=-5.14 ; P<0.001)$.

At both time points, bankers scored significantly more positively than non-bankers on function, symptom and total scores, and there were significant improvements over time on all three measures for the total sample. The absence of significant bank $\times$ time interactions indicated that both bankers and non-bankers improved to comparable extents. Mean scores and F-ratios are shown in Table 4.

Predictors of decision to bank in those unsure about whether or not they want children in the future. In a subsample of men $(n=36)$ who were unsure about whether they wanted children in

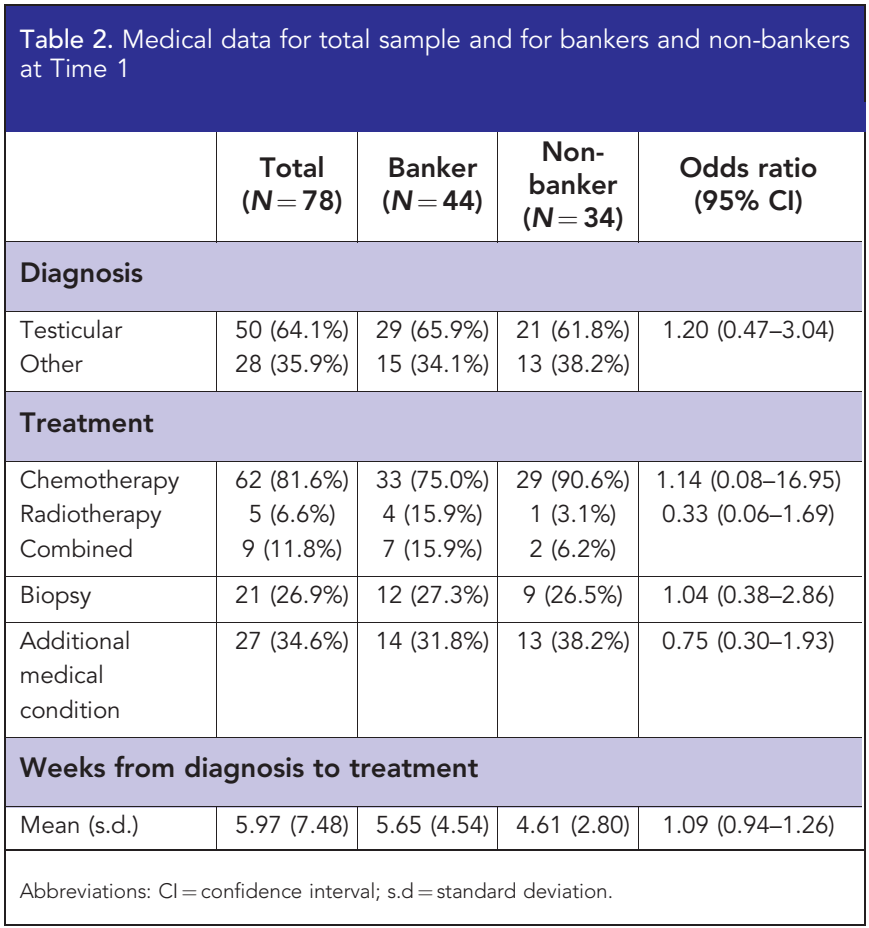

the future, $24(66.7 \%)$ chose to bank sperm. Men who chose to bank sperm were less likely to have children compared with nonbankers $(20.8$ vs $83.3 \%$; $P<0.001)$. As shown in Table 5 , they were significantly younger, reported greater satisfaction with the quality of time in appointments, less worry about children born from banked sperm and about effects of cancer treatment on children born after treatment than those who did not bank. Those who chose to bank were significantly more sure about what to do, were clearer about the decision that was best for them and more strongly agreed with the statement 'If I don't bank now, I think I will regret it later.' At T2 there were no differences between bankers and non-bankers in this subgroup, except that bankers reported it was more important to know about changes in their fertility than non-bankers $(4.33 \pm 0.87$ vs $2.70 \pm 1.34 ; t(32)=-4.25 ; P<0.001)$.

\section{DISCUSSION}

Previous work has identified a number of variables associated with men's decisions about sperm banking on diagnosis. We sought to extend these findings and consider the implications of these decisions 1 year later. Our finding that just over half the sample (56.4\%) chose to bank their sperm before commencing cancer treatment is higher than reported in previous work (reviewed by Pacey and Eiser, 2011). Comparable figures have ranged from as low as $2.9 \%$ in Taiwan (Chang et al, 2006) to $24 \%$ in the United Status (Schover et al, 2002; Girasole et al, 2007). The higher rate found in our study might be expected given that at both recruitment sites, sperm banking is offered free of charge in accordance with NICE guidelines (National Collaborating Centre for Women's and Children's Health, 2004). Staff were well informed about the rationale for sperm banking and had relatively easy access to large wellestablished sperm banks.

Our findings are consistent with much previous work describing characteristics of why men bank sperm (Lass et al, 2001; Schover et al, 2002; Saito et al, 2005; Girasole et al, 2007). Men who bank sperm are more likely to be younger, less likely to have children and especially more likely to want a child in the future. Despite measuring a wider range of variables than previously reported, we found that the only variable that predicted between bankers and non-bankers on diagnosis was their desire for children.

Table 3. Hierarchical logistic regression to distinguish between bankers and non-bankers (Time 1)

\begin{tabular}{|c|c|c|c|c|c|c|}
\hline & \multicolumn{2}{|c|}{ Demographic } & \multicolumn{2}{|c|}{+ Quality of life } & \multicolumn{2}{|c|}{$\begin{array}{l}+ \text { Views about sperm } \\
\text { banking and desire for } \\
\text { children }\end{array}$} \\
\hline & OR $(95 \% \mathrm{Cl})$ & Sig. & OR $(95 \% \mathrm{Cl})$ & Sig. & OR $(95 \% \mathrm{Cl})$ & Sig. \\
\hline Age (at questionnaire) & $0.25(0.13-0.51)$ & $<0.001$ & $0.21(0.10-0.46)$ & $<0.001$ & $0.46(0.17-1.23)$ & 0.124 \\
\hline Have children already (no) & $2.78(0.89-8.72)$ & 0.079 & $2.27(0.68-7.53)$ & 0.180 & $1.92(0.41-8.92)$ & 0.405 \\
\hline $\begin{array}{l}\text { Total HRQoL } \\
\text { (highest HRQoL) }\end{array}$ & & & $3.39(1.10-14.10)$ & 0.036 & $0.62(0.10-3.95)$ & 0.615 \\
\hline $\begin{array}{l}\text { Knowing my sperm is/was banked makes me feel } \\
\text { more of a complete man (agree) }\end{array}$ & & & & & $0.88(0.13-5.78)$ & 0.890 \\
\hline If I don't/didn't bank now, I think I will regret it later & & & & & $1.83(0.75-4.44)$ & 0.184 \\
\hline Effect of cancer on wish for children & & & & & $1.80(0.50-6.46)$ & 0.366 \\
\hline Desire for children in the future & & & & & $5.13(1.72-15.23)$ & 0.003 \\
\hline
\end{tabular}


Table 4. Comparisons of quality of life between bankers and non-bankers at T1 and T2: means and F-ratios

\begin{tabular}{|c|c|c|c|c|c|c|c|}
\hline \multirow[b]{3}{*}{ HRQoL } & \multicolumn{4}{|c|}{ Means and (s.d.) } & \multicolumn{3}{|c|}{$\mathrm{F}(1,75)$ and $P$-values } \\
\hline & \multicolumn{2}{|c|}{ Bankers $(N=43)$} & \multicolumn{2}{|c|}{ Non-bankers $(N=34)$} & \multirow[t]{2}{*}{ Bank } & \multirow[t]{2}{*}{ Time } & \multirow[t]{2}{*}{ Bank $\times$ time } \\
\hline & Time 1 & Time 2 & Time 1 & Time 2 & & & \\
\hline Function & $82.67(15.24)$ & 89.65 (12.09) & $74.49(15.86)$ & $84.05(20.82)$ & $4.82(0.031)$ & $18.67(<0.001)$ & $0.45(0.503)$ \\
\hline Symptoms & $11.74(11.71)$ & $9.49(11.36)$ & $21.01(16.63)$ & $14.85(20.23)$ & $6.38(0.014)$ & $5.08(0.027)$ & $1.10(0.299)$ \\
\hline Total & $85.43(12.56)$ & $89.58(11.27)$ & 76.59 (15.33) & $84.20(19.93)$ & $5.99(0.017)$ & $11.17(<0.001)$ & $0.97(0.328)$ \\
\hline
\end{tabular}

Table 5. Summary of results predicting decisions to bank among those unsure about their desire for children in the future

\begin{tabular}{|c|c|c|c|c|}
\hline & $\begin{array}{l}\text { Banker } \\
(N=24)\end{array}$ & $\begin{array}{c}\text { Non- } \\
\text { banker } \\
(N=12)\end{array}$ & & \\
\hline & $\begin{array}{l}\text { Mean } \\
\text { (s.d.) }\end{array}$ & $\begin{array}{l}\text { Mean } \\
\text { (s.d.) }\end{array}$ & OR $(95 \% \mathrm{Cl})$ & Sig. \\
\hline Age (years) & $29.11(7.59)$ & $35.23(7.20)$ & $0.42(0.19-0.95)$ & 0.037 \\
\hline $\begin{array}{l}\text { Satisfaction with } \\
\text { appointments }\end{array}$ & $4.25(0.46)$ & $3.74(0.59)$ & $8.74(1.34-56.97)$ & 0.023 \\
\hline $\begin{array}{l}\text { Satisfaction with } \\
\text { quality of time at } \\
\text { appointments }\end{array}$ & $4.19(0.53)$ & $3.43(0.90)$ & $3.33(1.32-8.42)$ & 0.011 \\
\hline $\begin{array}{l}\text { Worry that children } \\
\text { born from banked } \\
\text { sperm will have } \\
\text { health problems }\end{array}$ & $2.29(0.86)$ & $3.25(0.87)$ & $0.25(0.08-0.76)$ & 0.015 \\
\hline $\begin{array}{l}\text { Worry that my } \\
\text { cancer treatment } \\
\text { could cause health } \\
\text { problems for } \\
\text { children born } \\
\text { afterwards }\end{array}$ & $2.46(0.93)$ & $3.42(0.99)$ & $0.30(0.11-0.81)$ & 0.018 \\
\hline $\begin{array}{l}\text { I am/was unsure } \\
\text { what to do }\end{array}$ & $3.21(0.83)$ & $2.50(0.67)$ & $0.38(0.16-0.89)$ & 0.025 \\
\hline $\begin{array}{l}\text { It is/was clear what } \\
\text { choice is/was } \\
\text { best for me }\end{array}$ & $3.38(0.65)$ & $2.75(0.75)$ & $2.71(1.10-6.67)$ & 0.031 \\
\hline $\begin{array}{l}\text { If I don't/didn't } \\
\text { bank now, I think } \\
\text { I will regret it later }\end{array}$ & $3.08(0.78)$ & $2.33(0.78)$ & $3.83(1.23-11.90)$ & 0.020 \\
\hline
\end{tabular}

Abbreviations: $\mathrm{Cl}=$ confidence interval; s.d. $=$ standard deviation; sig = significance

After 1 year, those who banked felt their fertility had been less compromised and recognised the value of knowing about changes in fertility, perhaps reflecting greater awareness about the possibility of fertility recovery than nonbankers.

It is easy to understand that the decision to bank is highly motivated by a desire for children, so what is perhaps more interesting is what men take into account when they are not certain they want children in the future. Among a subsample unsure about whether or not they wanted children in the future, those who banked were more satisfied with quality of their clinic appointments and had less concerns about the health of children born after cancer treatment. They also reported that their decision to bank was in part motivated to avoid regret in the future. Many young men who are faced with the diagnosis of cancer may have never thought about whether or not they want children in the future. It is therefore especially important that clinicians take time to discuss fertility options with these men and address specific concerns, such as the health of future biological children.

Previous work also suggests the advice of the oncologist is important in helping men decide whether to bank sperm (Yee et al, 2011). We previously found that men relied on oncologists to arrange appointments at the sperm bank and that men were more likely to bank where they held more positive views about the clinic consultations before banking (Eiser et al, 2011), again suggesting that medical staff play a critical role in facilitating decisions about banking.

Although a number of studies have investigated HRQoL in men following testicular cancer (Rossen et al, 2009), no past work has specifically investigated how far HRQoL is affected by sperm banking, either on diagnosis or in the longer term. On diagnosis, we found that bankers reported better HRQoL and fewer symptoms than non-bankers, perhaps suggesting that those who agree to bank do so in part because they feel strong enough to undertake the extra clinic appointments necessary, or feel more optimistic about their survival and therefore think it is more worthwhile. These differences between bankers and non-bankers persisted 1 year later, while, as might be expected, HRQoL improved for both groups over this period. Thus, although the decision to bank sperm was associated with better HRQoL, our findings do not support a causal interpretation that subsequent $\mathrm{HRQOL}$ is enhanced by deciding to bank.

Limitations. Our follow-up (1 year) was relatively short. At this time, men may not be aware whether or not their fertility has recovered. We recruited men with good prognoses and decisions may be far more complex for those where the outcomes are less clear. More extensive medical data (including staging) would be valuable in future work. We used standardised questionnaires where possible but given that there has been relatively little previous work in the United Kingdom, we made changes to previously reported scales to be culturally appropriate and developed others. These varied in reliability and suggest that a priority for future work is to develop standardised measures that are sensitive to the issues relevant to men whose fertility is potentially compromised because of cancer treatment. This work was conducted in two centres in the United Kingdom, both of which offered free banking and storage for men with cancer. Previous work is not always clear about whether or not men have to pay for long-term storage, and this may account for some 
differences in findings associated with the policy of different health-care systems.

Work of this kind is often criticised for poor response rates, attributed to men's general reluctance to take part in health-related research (Kraemer, 2000). In fact, our initial response rate of $86.67 \%$ was relatively good and remained so at the 1 -year followup $(85.7 \%)$, suggesting perhaps that fertility is a highly important issue for these men.

\section{CONCLUSION}

Previous work suggesting that few men are willing to bank sperm may in part be a consequence of methodological problems, especially where no account is taken of whether or not men already have children or wish to have a child in the future. We conclude that the principal reason why men bank sperm on diagnosis is whether or not they want to have children in the future. The implications are that men may sacrifice their chance to have children because they do not anticipate how they might feel about this in the future. For those men who are uncertain about future reproductive plans, decisions depend more on their HRQoL on diagnosis and satisfaction with clinic care. Among this group, those who did not bank were younger, less likely to have had children, more concerned about the health of children born after cancer and less certain about what they should do. We conclude that these men deserve sensitive counselling that promotes consideration of the future consequences of compromised fertility.

\section{ACKNOWLEDGEMENTS}

This paper was supported by funding from Cancer Research-UK to C Eiser, A Pacey and R Rowe (C481/A8141). The authors would like to thank Dr. Vinay Sharma for helping with access to sperm banking records in Leeds.

\section{REFERENCES}

Aaronson NK, Ahmedzai S, Bergman B, Bullinger M, Cull A, Duez NJ, Filiberti A, Flechtner H, Fleishman SB, de Haes HCJM, Klee M, Osoba D, Razavi D, Rofe PB, Schraub S, Sneeuw K, Sullivan M, Takeda F (1993) The European Organisation for Research and Treatment of Cancer QLQ-C30: a quality of life instrument for use in international clinical trials in oncology. J Natl Inst Cancer 85: 365-376.

Achille MA, Rosberger Z, Robitaille R, Lebel S, Gouin J-P, Bultz BD, Chan PTK (2006) Facilitators and obstacles to sperm banking in young men receiving gonadotoxic chemotherapy for cancer: the perspective of survivors and health care profession. Hum Reprod 21: 3206-3216.

Broadbent E, Petrie KJ, Main J, Weinman J (2006) The Brief Illness Perceptions Questionnaire. J Psychosom Res 60: 631-637.

Chang HC, Chen SC, Chen J, Hsieh JT (2006) Initial 10-year experience of sperm cryopreservation services for cancer patients. J Formos Med Assoc 105: 1022-1026.

Eiser C, Arden-Close E, Morris K, Pacey AA (2011) The legacy of sperm banking: How fertility monitoring and disposal of sperm are linked with views of cancer treatment. Hum Reprod 26: 2791-2798.

ESHRE (2004) Taskforce 7: ethical considerations for the cryopreservation of gametes and reproductive tissues for self-use. Hum Reprod 19: $460-462$.

Fayers P, Aaronson NK, Bjordal K, Sullivan M (1995) EORTC QLQ-C30 Scoring Manual. EORTC Quality of Life Study Group: Brussels, Belgium. Ganz PA (2010) Harnessing personalised medicine to prevent late effects. Lancet Oncol 11: 7-9.
Gilbert E, Adams A, Mehanna H, Harrison B, Hartshorne GM (2011) Who should be offered sperm banking for fertility preservation? A survey of UK oncologists and haematologists. Ann Oncol 22: 1209-1214.

Girasole CR, Cookson MS, Smith JA, Ivey BS, Roth BJ, Chang SS (2007) Sperm banking: use and outcomes in patients treated for testicular cancer. BJU Int 90: 33-36.

Green D, Galvin H, Horne B (2003) The psycho-social impact of infertility on young male cancer survivors: a qualitative investigation. Psycho-Oncology 12: $141-152$.

Hayden PJ, Keogh F, Conghaile MN, Carroll M, Crowley M, Fitzsimon N, Gardiner N, Vandenberghe E, O'Riordan J, McCann SR (2004) A single-centre assessment of long-term quality-of-life status after sibling allogeneic stem cell transplantation for chronic myeloid leukaemia in first chronic phase. Bone Marrow Transplant 34: 545-556.

Hinz A, Einenkel J, Briest S, Stolzenberg J-U, Papsdorf K, Singe S (2012) Is its useful to calculate sum scores of the quality of life questionnaire EORTC QLQ-C30? Eur J Cancer Care 21(5): 677-683.

Hjermstad MJ, Fossa SD, Oldervoll L, Holte H, Jacobsen AB, Loge JH (2005) Fatigue in long-term Hodgkin's disease survivors: a follow-up study. J Clin Oncol 23: 6587-6595.

Hosmer DW, Lemeshow S (2000) Applied Logistic Regression. 2nd edn (Wiley: New York.

Klosky JL, Randolph ME, Navid F, Gamble L, Spunt SL, Metzger ML, Daw N, Morris EB, Hudson M (2009) Sperm cryopreservation practices among adolescent cancer patients at risk for infertility. Pediatr Haematol Oncol 26: $252-260$.

Kraemer S (2000) The fragile male. BMJ (Clin Res ed) 321: 1609-1612.

Lass A, Akagbosu F, Brinsden P (2001) Sperm banking and assisted reproduction treatment for couples following cancer treatment of the male partner. Hum Reprod 7: 370-377.

Lee SJ, Schover LR, Partridge AH, Patrizio P, Wallace WH, Hagerty K, Beck LN, Brennan LV, Oktay K (2006) American Society of Clinical Oncology Recommendations on fertility preservation in cancer patients. J Clin Oncol 24: 2917-2931.

Loblaw A, Bezjak A, Bunston T (1999) Development and testing of a visitspecific patient satisfaction questionnaire: The Princess Margaret Hospital Satisfaction with Doctor Questionnaire. J Clin Oncol 17: 1931-1938.

Magelssen H, Haugen TB, von Düring V, Melve KK, Sandstad B, Fossa SD (2005) Twenty years experience with semen cryopreservation in testicular cancer patients: who needs it? Eur Urol 48: 779-785.

Mykletun A, Dahl AA, Haaland CF, Bremnes R, Dahl O, Klepp O, Wist E, Fossa SD (2005) Side effects and cancer-related stress determine quality of life in long-term survivors of testicular cancer. J Clin Oncol 23: 3061-3068.

National Collaborating Centre for Women's and Children's Health (2004) Fertility: Assessment and Treatment for People with Fertility Problems. Commissioned by the National Institute for Clinical Excellence. RCOG Press: London, UK, ISBN: 1-900364-97-2 (February).

Neal MS, Nagel K, Duckworth J, Bissessar H, Fischer MA, Portwine C, Tozer $\mathrm{R}$, Barr RD (2007) Effectiveness of sperm banking in adolescents and young adults with cancer. Cancer 110: 1125-1128.

Office for National Statistics (2012) Cancer Statistics Registrations. Office for National Statistics: UK, Series MB1, No. 41, 2010.

Pacey AA, Eiser C (2011) Banking sperm is only the first of many decisions for men: What healthcare professionals and men need to know. Hum Fertil 14: 208-217.

Pacey AA, Merrick H, Arden-Close E, Morris K, Barton LC, Crook AJ, Tomlinson MJ, Wright E, Rowe R, Eiser C (2012) Monitoring fertility (semen analysis) by cancer survivors who banked sperm prior to cancer treatment. Hum Reprod 21: 3132-3139.

Pacey AA (2003) Sperm you can bank on. BMJ 327: 1354.

Pacey AA (2007) Fertility issues in survivors of adolescent cancers. Cancer Treat Rev 33: 646-655.

Quinn GP, Murphy D, Knapp C, Stearsman DK, Bradley-Klug KL, Sawczyn K, Clayman ML (2011) Who decides? Decision making and fertility preservation in teens with cancer: a review of the literature. $J$ Adolesc Health 49: 337-346.

Rossen PB, Pederson AF, Zachariae R, von der Maase H (2009) Health-related quality of life in long-term survivors of testicular cancer. J Clin Oncol 27: 5993-5999.

Royal College of Physicians (2007) The Effects of Cancer Treatment on Reproductive Functions. Guidance on Management. Royal College of Physicians: London, P72. 
Saito K, Suzuki K, Iwasaki A, Yumura Y, Kubota Y (2005) Sperm cryopreservation before cancer chemotherapy helps in the emotional battle against cancer. Cancer 104: 521-524.

Schover LR, Rybicki LA, Martin BA, Bringelsen KA (1999) Having children after cancer. A pilot survey of survivors' attitudes and experiences. Cancer 86: 697-709.

Schover LR, Brey K, Lichtin A, Lipschultz LI, Jeha S (2002) Oncologists' attitudes and practices regarding banking sperm before cancer treatment. J Clin Oncol 20: 1890-1897.

Snyder CF, Garrett-Mayer E, Blackford AL, Brahmer JR, Carducci MA, Pili R, Stearns V, Wolffe AC, Dy SM, Wu AW (2009) Concordance of cancer patients' function, symptoms, and supportive care needs. Qual Life Res 18: 991-998.

Tschudin S, Bitzer J (2009) Psychological aspects of fertility preservation in men and women affected by cancer and other life-threatening diseases. Hum Reprod Update 15: 587-597.
Wallace WHB, Thomson AB (2003) Preservation of fertility in children treated for cancer. Arch Dis Child 88: 493-496.

Yee S, Fuller-Thomson E, Dwyer C, Greenblatt E, Shapiro H (2011) 'Just what the doctor ordered': factors associated with oncology patients' decision to bank sperm. Can Urol Assoc J 6: E174-E178.

Zapzalka DM, Redmon JB, Pryor JL (1999) A survey of oncologists regarding sperm cryopreservation and assisted reproductive techniques for male cancer patients. Cancer 86: 1812-1817.

This work is published under the standard license to publish agreement. After 12 months the work will become freely available and the license terms will switch to a Creative Commons AttributionNonCommercial-Share Alike 3.0 Unported License. 